\title{
THE RIGHTS OF THE STATELESS AND THEIR PROBLEMS IN STATE OF KUWAIT
}

\author{
Saad Obaid Jafar Al-Hajiri \\ PhD Candidate, Department of Shariah and Law, \\ Academy of Islamic Studies, \\ University of Malaya, 50603 Kuala Lumpur. \\ S.s188@hotmaill.com \\ Narizan Abdul Rahman \\ Senior Lecturer, Department of Shariah and Law \\ Academy of Islamic Studies, \\ University of Malaya, 50603 Kuala Lumpur. \\ izan@um.edu.my \\ Abdullah Al-Mikhlafi \\ Lecturer, Department of Shariah and Law \\ Academy of Islamic Studies, \\ University of Malaya, 50603 Kuala Lumpur. \\ Aalmekhlafi_62@yahoo.com
}

\begin{abstract}
This study deals with an issue that is not specific to the nationality of the State of Kuwait. This issue is considered one of the most important issues in the country of Kuwait. It abut depriving the stateless of political and social rights. In this research, we will address the human and social rights that they enjoy and which they may be deprived of. The research also aims to explain the problematic nature of this issue to the society if it is not resolved by the appropriate solution. The importance of this research enables us to know the solutions of the issue, and discussed these solutions by descriptive analytical to come up with a radical solution that ends the suffering of that category.
\end{abstract}

Keywords: the rights, the stateless, problems, Kuwait 


\section{INTRODUCTION}

The issue of the stateless residents is considered as one of the most important issues in the political controversy, and a basis for intensive human rights deliberation on the dimensions of this issue and its intricate approaches in Kuwait. The importance of such issue arises from the attention paid to it by the media in that hundreds of daily articles, reports and investigations have been written about this phenomenon which is characterized by its political, social, and legal complexity. Undoubtedly, it could be said that the issue of the stateless residents has become a concurrent, chronic, and complex problem whose risk increases with the passage of time, and whose severity worsens with the succession of years.

Moreover, it could be said that the existence of such a category constitutes a political, social, and legal issue with significant problematic dimensions in the region as a result of its worsening legal and humanitarian conditions. Within this respective, this category forms an issue whose risk increases and worsens with the passage of time and succession of years unless radical solutions are found to close this file at once.

The stateless residents in their current positions are simply deprived of their political, social, and educational rights as a result of having no citizenship in the countries where they live. The legal side of this category has constituted a topic for political discussion which is stirred up by the local and international human right organizations that are demanding appropriate solutions to enable this social category to exercise their various humanitarian and social rights.

Thus this research aims at defining the category of the stateless in Kuwait, and clarifying the legal problems related to them, and developing suitable solutions to this problem.

The significance of this research lies on its being one of the permanent attempts that intends to tackle the rights of the category of the stateless in Kuwait and find radical solutions to such an issue.

The most important studies that have discussed this problem are a study by Rashid Al-Anzi (1994) entitled The Bedoons in Kuwait: A Legal Study of their Residence Project, another study by the same researcher entitled Legitimacy of the Bedoon Residence or the Stateless in Kuwait, a study by Ghanim AlNajar (1996) entitled The Issue of the Statelessness in Kuwait: Development and Future Possibilities); a study by Faris Matar Al-Wiqyan (2007) entitled Stateless People in Kuwait: the Crisis and its Repercussions. 
In order to achieve the objectives of this research, it has been divided into three chapters:

The first chapter: the characteristics of the stateless category. The second chapter: the problems of the stateless category. The third chapter: the struggle over the rights of the stateless category. The researcher has reached several important conclusions:

a) The study recommends the decision makers to find objective solutions to correct the legal rights of the members of this category as far as possible in such a way that does not conflict with the general interests of the society.

b) The study also recommends taking this issue out of the circle of ideological deliberation which is based on the individual class interest and placing it in the circle of the national issues that need objective vision that prioritizes the public interest over all others.

\section{CHARACTERISTICS OF THE STATELESS CATEGORY}

\section{The Stateless are among the Priorities of the Kuwait Society}

The issue of the stateless or the Bedoons ranks fifth among nineteen political, economic and social priorities in Kuwait, and this issue is at the top of other major vital issues, such as mediation, administrative corruption, drugs, health care, unemployment, applying Sharia law, promoting education, youth issues, trade of residencies, privatization, efficiency of security systems, environmental problems, regulation of the stock market, foreign investments, and Kuwait media (Rashid Hamad Al-Anzi, 1994: 81). Therefore, this proves the depth, importance, and seriousness of this issue at all the different socioeconomic levels and dimensions.

The label Bedoons is often used to refer to (the stateless residents), and this label is the most common used to refer to this category in Kuwait; it is also used in media and in the political, social, and cultural life, and as indicated by the term (the Bedoons), it means that this category has no specific nationality or without nationality. Other labels are also used, such as (the Bedoon residents) or (the illegal residents) which are all adopted by the state to refer to this category (Ibid: 82).

Their origin go back to ethnic Bedouin (nomadic) tribes from desert and pastoral areas on the outskirts of Saudi Arabia adjacent Kuwait and bordering Iraq and the thresholds of the eastern bank of the Gulf, and the origins of some of them even go back to the Desert of Syria, Jordan, Iraq and Saudi Arabia, 
coming from large Arabic tribes like Shamar and Anza (Ahmed Abdualhameed Ashosh, Omar Abu Bakr Bakhashab, 1990: 216)(The Bedoons) is a popular word that is widely used to call those social categories which could not prove their nationality to the state where they live, and their members do not have a proof of their affiliation or nationality to any other states (Ibid: 217). The word (Bedoons) is not a legal term but rather a general term which is commonly used to refer to the social categories whose members do not carry any specific nationality.

The concept of (the Bedoons) has various implications since it symbolizes the statelessness which means that the Bedoon member does not hold a specific nationality, and he could not prove his right of citizenship in accordance with the laws and regulations implemented in the country where he lives (Sami Khalifa, 2008: 5). Some define Kuwait Bedoons as: a group of people who belongs to the same ethnic, religious and cultural component of the original inhabitants of Kuwait; they often came from the (Arabian Peninsula, the region of Mesopotamia Bilad Arafidyan and Persia with simple groups from Bilad Alsham. Al-Wiqyan continued saying that they are a mixture of the majority that demonstrated their old presence in Kuwait as the statistics of $(1965,1970)$ showed, and a simple segment that proved their existence after all these years. Most of them do not hold any nationality and a few of them intentionally from Mesopotamia and Persia hid their documents so that they could enjoy the known privileges of the stateless who are known as the Bedoons in Kuwaiti Literature since their privileges were close to the rights of the Kuwaiti citizens until 1985 (Al-Anzi, 1994: 83).

The majority of the Bedoons are nomadic from the tribes of the north of the Arabian Peninsula who settled after the political borders appeared between the states of the region beside numbers of displaced people coming from the eastern shore of the Gulf of the Arabs and non-Arabs of Iran (Rashid Al-Anzi, 1994a: 192).

Furthermore, the Bedoons can also be defined as a group of individuals who live in some of the Arab Gulf states and who either do not hold specified nationality or hid their actual nationalities for some reason. This situation is a product of historical conditions related to immigration laws, nationality, naturalization, and the nomadic mobility of population which the region witnessed a year ago and after the establishment of the national state and demarcation of its borders (Fahd Al-Mikrad, 2005: 178).

There are definitely different points of view in interpreting, determining and analyzing the historical and social situations that led to the existence of the Bedoons in the Arab Gulf States. It is possible to get different ideological perceptions about the identity of the Bedoons some of which are true and some 
are not. When we want to reflect on the situation of this category's formation and its growth, we will find ourselves facing very highly complex social and political issue as well as conflicting, debatable and controversial accounts regarding the status of these categories, identity, role, function and factors of their evolution; there is the official discourse of the state which confirms that this category resides illegally on the land of the state, and its members have settled in the state to achieve economic interests and take advantage of the positive factors of life and work in the Gulf states; there is the general popular discourse which is divided into a proponent of these groups and an opponent of their existence; there is also the discourse of the members of these marginalized groups who, in terms of rights, demand the state to resolve their situation, grant them their full human rights, naturalize them, and integrate them into the social life (Mohammed Husain Al-Yusufi, 2004: 7).

The official discourse of the state confirms that (the Bedoons) are groups and individuals who came from neighboring areas and illegally settled in the country after they had destroyed their documents and passports in order to benefit from the economic and social situations after discovering the abundance of the oil in the state where great facilities were provided for the employees. According to this view, the existence of such categories of people is unlawful and illegal, and they therefore establish a legal residence on a land which is not their land and in a homeland which is not theirs either, and so they had better return to their original countries and resolve their legal situations (Ashosh \& Bakhashab, 1990: 223). And this view is confirmed by the successive governments which believe that (the Bedoons) are citizens who belong to other Arabic countries and who came to Kuwait to work in the late sixties and early seventies, and later on they hid their passports and identity hoping to benefit from the privileges that Kuwait Bedoons used to enjoy (AlAnzi, 1994a: 199).

At first glance it seems that the issue is very simple, but when one reflects on the depth of this issue, he will find himself in the face of a highly complex social phenomenon at its political, cultural, demographic, historical and legal levels. For a deeper understanding of such a phenomenon, a group of studies of all its aspects should be carried out to provide a social vision about the ethnical and political conditions of these groups, which are usually called (the Bedoons) or the stateless (Al-Yusufi, 2004: 8). 


\section{Population Weight of the Stateless}

Researchers admit the difficulty of taking an accurate information on the census of the stateless residents in the Arab Gulf States as a result of the great mystery that surrounds the conditions of this social category as well as the mystery surrounding their situations and the researcher can find statistical estimates of the general census of this category and their whereabouts. The constant heterogeneity and inconsistency between the official and estimated statistics is regarded as one of the major difficulties that a researcher encounters in the case of the stateless since numbers change and vary from time to time or simultaneously between the statements of the officials in the state and other institution at the same time and same date (Hussam Adeen Fathi Nasif, 1996: 156).

In the six Gulf States, the major problem of the stateless lies in Kuwait because of the very large population weight of this category since the Kuwait unofficial estimates show that the number of members of this minority reached about 350 thousand people before the invasion. In 1989, the state officially announced a census of the official numbers of the stateless persons based on the official statistics register, where the Minister of Planning announced that the Kuwait population of Kuwaitis reached less than $28 \%$ of the population and the number of the stateless people in this period constituted about 11.6 $\%$ (about 225 thousand) and their population then declined to about 117 thousand, i.e., after the Iraqi invasion to Kuwait. This declination is attributed to the procedures taken by the government to force a large segment of the stateless to reveal their original nationalities and amend their legal status in their countries, and so a large segment of this category left Kuwait and could not return after liberation which forced them to stay either in their countries of origins or in countries that accepted them as refugees (Al-Anzi, 1994: 88).

The population estimates show that $55 \%$ of the stateless population falls below the age of 15 and their family support rate reaches 7 persons at an average, and the percentage of those below the average education is $87 \%$ now since the illiteracy rate has increased after 1990.

According to the statistical data from the Civil Information Authority (CIVA), the number of the stateless people reached 220 thousands in June 1990 (Khalifa, 2008: 5). Some estimates can be found in the newspapers through the interviews with officials as the assistant undersecretary for Nationality and Passports Affairs, Sheik Ahmed Nawaf, has stated that the total number of the stateless people (on 29 January 1990) is 091435. Despite the apparent discrepancy in the statistical data, the current estimate of the number of the 
stateless people who are in Kuwait is today not more than 100 thousand (A1Mikrad, 2005: 180).

\section{Socio-Demographic Characteristics of the Stateless}

The human suffering of this category and the deprivation of its rights for long periods of time led to a huge negative accumulation in the social and humanitarian conditions to the extent that many researchers have come to say that this category with its tragic and miserable conditions has become a security threat to the whole society. Many scholars and thinkers fear the spread of the ideological extremism among the members of this group, where they can form a human sector that raises the saliva of the extremist ideological forces at home and abroad. And those who watch the media will find tons of writings that describe the tragic social reality and life of the members of this category (Qadri Abdulaziz, 2003: 139).

There is no doubt that these conditions of life have resulted in population reality that is essentially a reflection of the poverty, destitution, need, and illiteracy of the Bedoons, where the population structure is characterized by a large base of young people and large size of family, and this, in turn, increases the bad conditions of the social life of the members of this category.

\section{Demographic Characteristics of the Stateless}

a) The majority of the stateless category are children who are under the age of fifteen and who represent about $85 \%$ of the total number of the Bedoons.

b) The majority of the stateless are illiterate and those who have limited education where the percentage of those below the average education reached $87 \%$.

c) The family in this category of the stateless is characterized by its large size, where the family support rate reaches (7) persons at an average while it is not more than (4.5) in the Kuwaiti family and the significance of this matter could be seen in terms of the economic burden and exhaustion of public services in the present and future (Ashosh \& Bakhashab, 1990: 230).

d) The majority of this minority are limited to certain nationalities, as the project to complete the special documents of the stateless led to the verification of (27.470) nationalities, i.e. (12.5) people of the total category. Before 1989, the government had not declared a specific number of the stateless persons, and more than one scientific reference on (the Bedoons) attributed this to the fact that the government lacked the accurate statistics in this regard. 
It is clear through these characteristics that the demographic structure is problematic in nature since it includes humanitarian and moral aspects which make the treatment of these problems difficult and complex on the humanitarian and ethnic level (Nasif, 1996: 157).

\section{THE PROBLEMS OF THE STATELESS CATEGORY}

\section{The Problems of the Stateless in Kuwait}

The issue of the stateless takes the form of a worsening, chronic, complex, social and legal crisis. It is a segment in the society suffering from great humanitarian and social difficulties, which is a Kuwaiti crisis associated with the reality of the political life and the population structure and the question of identity in the country. The problem of the stateless in Kuwait is very complex at the various levels and figurations of this issue. It is noteworthy that the problem of the stateless in Kuwait has been given much of the media coverage, as the issue has been the focus of discussion and debate in Kuwait for half a century (Shams Adeen al-Wakeel, 1991: 304).

The crisis of the stateless in Kuwait is different from that in the Gulf States and others in terms of the size of this category which amounted to 225 thousand people before the invasion according to the informal statistics, and then this number gradually decreased to less than 100 thousand people after the Iraqi invasion of Kuwait. These numbers are enormous in comparison with those in the UAE, Qatar and Saudi Arabia in which the number of this category did not exceed 10 thousand people and a few thousand in Saudi Arabia or Qatar (Al-Anzi, 1994: 96).

This means that we must admit that the size of this category is very large in terms of the demographic and economic standards in Kuwait, and therefore its integration into the society puts the country in many calculations that might be absent in those of the advocates of the naturalization rights and full integration of these groups in the society. However, part of this crisis has taken on a growing human nature in the international forums which put Kuwait in the siege of international attitudes and the organizations that are mobilizing all their capabilities to demand Kuwait to naturalize this category and grant its political and social rights immediately beside the accusation that Kuwait does not respect human rights and this leads to present a globally negative image of the political system in Kuwait (Khalifa, 2007: 5).

At the security level, scholars and researchers say that the stateless people pose a great security threat to the social, cultural, and political life in Kuwait. 
That is because the rate of crime, drugs, illiteracy and unemployment is high among this social segment, and it may be easy to incite these groups against the state and society due to the worsening of their political conditions. In other words, this category has become a source of a great threat if the state does not act quickly to find radical solutions to the conditions of this social group with being obliged to do so no matter how long (Abdulaziz, 2003: 142).

The issue of the stateless was also of concern to the authorities in Kuwait because they had to set up a special legal situation controlled by the necessity to respect the human rights in light of the recent global trend to such human rights respect. What is worthwhile is that the issue of the stateless is remarkably still the first issue in the Kuwaiti National Assembly in that the debate on this issue takes its time at the various stages. The periodic parliamentary quarrels and disputes arise among deputies with one another on the one hand and between deputies and the government on the other hand, and this parliamentary debate takes the form of an ideological and political struggle that does not depend on the strategies that must be adopted in amending the conditions of this group, as there are those calling for the naturalization of the members of this category, there are those calling for political and civil rights, and there are those who strongly reject this asking to harass the members of this category and deport them (Al-Anzi, 1994: 97).

\section{The Essence of the Problem facing the Stateless}

Whatever the account marketed and promoted about the origins of the stateless, their historical positions and the ways they adopted to enter the Gulf States, and whatever the demographic and population positions that led to their presence, the problem of the stateless lies in their presence in the Gulf States before the independence and a little after it, as the members of these groups participated in the process of development, defense, construction, and security and formed structural social segments in these countries (Ashosh \& Bakhashab, 1990: 235). Moreover, their social situations have witnessed a great fluctuation between the encouragement of countries at first to their presence because of the need for them in the development process and between restriction on them in some periods of time and their rejection altogether in other periods of time, especially when this issue became highly apparent and the specter of naturalization started to threaten the demographic structure in some of these countries such as Kuwait, where it includes the largest segment of the population of these marginalized groups, which constitutes a significant threat to the demographics according to the official account. 
In my point of view, the essence of the problem lies in the negligence of this marginalized category from the beginning since such negligence of its conditions by the governments of the Gulf States led to greatly exacerbate the indications of its demographic and humanitarian presence. These categories have been characterized by a relatively high population growth over time, and the neglect of naturalization of the real deserving categories led to the exploitation of this situation by the new immigrants who claimed their affiliation to this category to benefit from the privileges they used to enjoy especially in the first phase of the state independence where the state recognized their existence and their legitimacy in view of the prevailing economic and political conditions of that time (Nasif, 1996: 159).

The most complex point in the stateless situation is that they are not classified as refugees either, as the refugee is defined as: "any person living outside the country of which he holds its nationality for his fear of being persecuted because of his race, religion, nationality, belonging to a certain group or because of his political opinions, and he cannot return to his homeland or does not want to. Furthermore, the stateless do not have citizenship and consider the state in which they live as their home country as well as their safe haven. Consequently, the civil and legal status of the stateless is fully consistent with the provisions of the United Nations Convention regarding the status of the stateless persons of 1945, which defines a stateless person as: "a person whose country does not consider him as its citizen under its legislation" (Al-Anzi, 1994: 98).

\section{The Problem of the Governmental Dealing with the Stateless in Kuwait}

The facts, events and studies have shown that a large part of the problem of the stateless is attributed to the governmental and official dealing with the members of this category over a half century, i.e., from the beginning of the independence until the present moment. The relationship between the state and the stateless has taken on a problematic and contradictory nature, and this is one of the reasons for the exacerbation of the crisis of the stateless and their problems in Kuwait (Al-Anzi, 1994a: 202).

This relationship takes a three-dimensional picture in that in the first phase, since the independence until 1986, it was characterized by acceptance, satisfaction, support, and encouragement, and then this situation turned upside down when the state adopted anti-Bedoon policy in 1986 (Al-Yusufi, 2004: 9).

By the end of 1986, the era of honey between the category of the stateless and the official authorities in Kuwait has ended in that a radical change took place in the way the Kuwaiti government dealt with the issue of the stateless and the concept and the political procedures changed from a stage that was 
based on considering them as non-Kuwaiti citizens temporarily, according to the official and media statements, to the relationship of denial and rejection of the legitimacy of their residence and existence and their rights of naturalization.

The reason for this shift in dealing with the stateless is attributed to the national internal and regional external situations of the political and security climate in Kuwait in the meantime which was full of confrontations and clashes between the government and the Kuwaiti opposition forces (Hasan al-Hadawi, 1973: 201).

The official authorities have later initiated the formulation of a ministerial committee with a high level of responsibility including a group of senior security men, judges, and experienced figures, and this committee has created, in turn, a mini technical committee to develop a precise strategy to deal with the segment of the stateless in Kuwait. And it was normal that those figures and visions keep up with the tense security atmosphere which was prevailing in Kuwait leading to more restriction on them as far as possible, and here the relationship between the stateless and the official authorities has changed and taken a convoluted path (Al-Anzi, 1994: 102). The counter policy continued until 1990 when a more violent policy began, called the policy of accusation, where the government' restriction on this category, due to the political situation, was so excessive that some segments of the stateless were accused of collaborating with the Iraqi regime in its aggression against Kuwait.

According to this perception, it is possible to say that the stateless groups were national loyalists in the 1960s, and then they turned into undesirable categories that were warned of in the 1990s, and then into accused groups in the last decade of the last century (Ashosh \& Bakhashab, 1990: 243). In this context, the scholars note that the first political coup against the members of this category arose under the influence of the Iran-Iraq war and the fear of the collaboration of some segments of this category with Iran.

Then the second coup took place after the invasion of Iraq, where some of the segments of these categories were accused of collaboration with the Iraqi enemy at the time. Thus the Iraqi-Iranian war and then the Iraqi invasion of Kuwait were a bad omen for these social categories.

Those interested in the issue of the stateless think that the most prominent reason for that change was the attitude taken by a group of the stateless within the Kuwaiti army in support of Iran, according to a security source. The reason for the change in policies may have been the expansion of the problem and increase their number significantly, and that the issue of naturalizing them means primarily more economic burdens. The government has taken a series of administrative procedures that have directly affected the size and quality of 
the material and social privileges that the stateless used to receive from (the welfare state) (Al-Anzi, 1994: 209).

Here, we must not forget the enormous sacrifices made by (the stateless) for the land of Kuwait in that (the stateless) formed the base of the army and provided a pattern of blessed sacrifices for Kuwait, and all Kuwaitis praised their great sacrifices and honorable struggle against the Iraqi invasion of Kuwait, as the largest number of martyrs who fell were from them, and some of them were imprisoned and some were captured.

The stateless participated in the defense of Kuwait in 2/8/1990 and specially the military stateless ones; some of them, therefore, were martyred, some were taken captive to Iraq, some went out with the Kuwaiti forces to Saudi Arabia and entered with the coalition forces in the war to liberate Kuwait, some returned to his family safe, and some of them sustained permanent disability. The number of martyrs of the stateless is 140 martyrs of the 600 Kuwaiti martyrs registered by the Office of Martyr (Al-Yusufi, 2004: 10).

In order to be more accurate, this issue is presented in its historical context by referring to some historical phases about the stateless:

a) When law 17 of 1959 about the residence of the foreigners was put, it clearly stated in Article 25, paragraph (D) of the law that among those excluded from the law are "members of the tribes or clans who enter Kuwait by land from the sides which they are accustomed to using to do their usual business", which could be seen as a clear lacuna in the law that allowed legal coverage of the problem since it was established (Rashid Al-Anzi, 1995: 28).

b) With the increasing advantages that the (Independence State) began to distribute in the early 1960s within the framework of the Kuwaiti citizens, including the stateless, many people began to immigrate to Kuwait legally or otherwise, wishing to enjoy the services of (the welfare state).

c) The coexistence and intermixing phase of the category of the stateless since the independence (the early sixties) and the successive Kuwaiti governments ignore of arresting and questioning them made many of them part of the social fabric of the State besides the official authorities considered them part of the Kuwaiti citizens when they were included in the statistics of the Ministry of Population Planning (Abdulaziz, 2003: 152).

d) In the mid-eighties the government began to change its policy towards this category and it seems that the first reason for this change is the attitude taken by a group of the stateless within the Kuwaiti army in support of Iran, according to security sources. 
e) The current phase, which covers the period from 1991 to the present day, and which is characterized by the attention of the official body of the need to solve the problem through the formation of a committee to revise the total segment into parts comprising different cases. They began to register those who claim that they are stateless and interview some of them as a step to complete the steps of the solution, it is the Central Committee of the Illegal Resident that is responsible to deal with (the stateless) (Ashosh \& Bakhashab, 1990: 246).

f) The Minister of the Interior has set up a set of conditions according to which a person is eligible to hold the nationality if he satisfies these conditions and a person who does meet these conditions becomes eligible. The required conditions are as follows:

a- Inclusion of (the stateless' names) in 1965 statistics.

b- An interview with the Nationality Committees that did its work in the early sixties.

c- The existence of Kuwaiti relatives of the first degree: there are a number of (stateless persons) who have relatives of the first degree holding the Kuwaiti nationality, and yet they have not been conferred the citizenship.

d- Permanent residence in Kuwait.

e- Study in Kuwait schools (Al-Hadawi, 1973: 204).

It is obvious that these conditions, in their best case, are applied to $20 \%$ of the current (stateless), and even if they are really applied and their results are directly carried out, it will represent only a partial solution. We can summarize the most important essential stages of the Bedoons situations in Kuwait as follows:

- The treatment of (the stateless) at the beginning, i.e. post-independence, was characterized by the criteria of equality, welcome and support, and (the stateless) did not suffer from any discrimination regarding jobs and rights, and they were admitted at schools and given the jobs as any Kuwaiti citizen.

- Since the mid-eighties the Kuwaiti government's policy began to change towards (the stateless) category and become more inclined to restrict them, specially in 1986 when they imposed a set of legal procedures that deprived them from the privileges that the state used to generously bestow on them since the independence (Al-Anzi, 1995: 30).

- In 1999, in the search for objective solutions to the problem of (the stateless), the state has promised to provide social benefits and fiveyear residence permits to individuals of (the stateless) who have given 
up their right to claim for the Kuwaiti nationality.

- In 2000, the Kuwaiti National Assembly passed a legal amendment on 16 March 2000, which made less than a third of the stateless people eligible to apply for the Kuwaiti nationality (Al-Anzi, 1994: 115).

\section{The Legal Status of the Stateless}

Under the complex circumstances of the political and social life in Kuwait before and after the independence, the state took several strict procedures that reflected negatively on the legal situations of (the Bedoons) in Kuwait. In the circle of this restrictiveness, (the stateless) lost many of their social rights that were bestowed on them at the early sixties and seventies of.

In last century, i.e. at the beginning of the national independence. The restrictiveness on the part of the government aimed to force (the stateless) that originally possessed hidden passport to confess their original identity and to leave Kuwait (Ashosh \& Bakhashab, 1990: 248).

The writers condemning the legal status of the stateless have highlighted this issue in the various written, virtual, and audio media and on the internet which was accompanied by a broad campaign by the international organizations calling for finding radical solutions to (the Bedoons) in Kuwait and in the other countries concerned with the issue. And one who takes a look will find that the stateless have suffered from a great siege that was reflected on their civil and social rights, which has no longer been a secret since it exists everywhere on the internet, in the media and in the political deliberation in the Kuwaiti National Assembly, and the rights of this group have become a public issue discussed by the individuals, community and the officials in the state as demanded by the international human right organizations (Al-Anzi, 1994a: 216).

In short, it can be said that the stateless were deprived of the rights of ownership, work, education, travel, and treatment. And these positions are reflected on their social conditions in terms of the spread of illiteracy, ignorance, drugs, and the crime rate, which constitutes a major security threat in the society. There is no doubt, therefore, that the legal file of the stateless has exceeded all the limits of the deliberation, debate, and discussion, and tons of press and media articles have been written around it.

It goes without saying that the picture of the legal situation is still very tragic. And the one who monitors the situation and events will find some kind of logical paradoxes, ethical contradictions, confusion, and hesitation in dealing with this file legally and politically (Al-Wakeel, 1991: 306). 
And multiple examples can be provided about the logical contradictions in dealing with the members of this category. For instance, in a response to a letter sent to the Ministry of Affairs from Teachers' Association in which the latter requested a report on the legal status of the enrollment of the male and female teachers who are stateless in the Association, the Ministry stated that it is not possible to accept the membership of the stateless because the membership is limited to the people of the Arab world, and thus they cannot be included in the category of Arabs.

This response was ridiculed by many because of its tough nature that does not reflect a cognitive and cultural understanding of the issue in the sense that most of the stateless people belong to the Arabic tribes known in the region and from the same ethnic and historical fabric of the tribes of the Kuwaiti citizens; this letter which the newspapers published has led to more negative accumulations in the hearts of the stateless persons, If the Ministry could deny their Kuwaiti citizenship because they do not obtain Kuwaiti nationality, it is displeased to state in the speech that they are outside the category of the Arab peoples (Al-Anzi, 1995: 33).

\section{STRUGGLE OVER THE RIGHTS OF THE STATELESS CATEGORY}

The treatment of this issue takes a shape that is governed by emotional and sentimental tendencies and drawn by private interests, intellectual disputes, ideological conflicts, contradictions of visions and moods, and the disagreement of improvisational attitudes.

\section{Justifications of the Trend that Denies the Rights of the Stateless}

It is never ironic that people think of preserving economic and social privileges which they used to enjoy and be acquainted with and fearing of losing those economic and social privileges of a society recognized by the regulations and natural laws of the nations and peoples. The Kuwaiti people, like any other people in the world, fear the deterioration of the situation and the loss of the abundant natural privileges that they comfortably enjoy.

It is natural for a group of politicians to oppose granting the citizenship to the stateless for considerations relating to economic and social privileges. And those of this trend, rejecting the integration of the stateless in Kuwait, find several pretexts and justifications which are the foundation of an opposing ideology to the rights of this category in citizenship and nationality (Al-Anzi, 1994: 125). 
Here, we must bear in mind that the supporters of this trend believe that the stateless are groups that intruded into the Kuwaiti society, though they are not of its social fabric and do not have citizenship rights originally. The dominant view is that those who are stateless have entered the country illegally and concealed their identities and passports and denied their nationality of origin, hoping for the privileges of living on the land of Kuwait and sharing with them, the Kuwaitis their natural rights to live freely on their land and enjoy its benefits as well as achievements of its civilizations.

It is natural for those who believe in this view that it ignores or pretends to ignore that a large segment of the stateless is from the people of the state, from the same origin, and from the tribes that have inhabited Kuwait since the beginning of its composition, and it is reiterated again that it is natural for those who believe in this ideological vision to deny the rights of (the Bedoons) without exceptions and to reject accepting them on the principle of citizenship and to provide arguments, pretexts and justifications that warn against their political and social danger (Ashosh \& Bakhashab, 1990: 252).

\section{Features of the Trend that Opposes Granting the Rights of the Stateless}

a) Those who believe in this view think that naturalization of (the stateless) and granting them their civil rights is an issue of the state and, therefore, this issue lies outside the circle of the political deliberation, forming a case in which neither any external party nor internal one has the right to interfere.

b) Granting (this category) its civil rights is a major threat to the national security of the state which comes from the privacy of this segment and its previous national affiliations because this category is full of affiliations and loyalties to other than Kuwait, and this is regarded very dangerous to the issue of loyalty to the state and the homeland, and granting this broad category the nationality may lead to a genuine threat to the national security and identity in Kuwait (Al-Hadawi, 1973: 209).

c) The economic and financial aspect of the issue of granting (the Bedoons) their civil rights constitutes one of the most important opposing reasons in granting the citizenship rights to this category. That is because granting nationality to this category costs the state highly in educating and housing them and in providing the privileges that are given to its Kuwaiti citizens. The new Kuwaiti will have a housing loan of 70,000 dinars $(210,000$ dollars), 4,000 dinars to the married person and a bonus of 50 dinars for each born child; he will be allowed to enjoy a minimum pension of 650 dinars and as well as the special bank loans. And this cost will be very large in terms of the economic and financial standard. 
d) The state wants to maintain the economic and social level of the citizens who start facing economic problems of a new type related to work, education opportunities, and health care, and thus this means that the naturalization of (the Bedoons) will generate great economic and financial problems by all standards (Faris Matar Al-Wiqyan, 2007: 90).

\section{Supporters of Naturalization and Citizenization}

The supporters of naturalization believe that the naturalization of (the Bedoons) and granting them their civil rights, is now a historical necessity dictated by the international laws, the logic of the times, and the legal documents, as dictated by the economic and social necessity of life, security, and progress in Kuwait. (The Bedoons) category is closely related to the economic and political life, and it constitutes an authentic segment of the society and its intellectual, cultural and social fabric is never different from the fabric of the Kuwaiti society. Moreover, leaving this category as it is now will cause major social and security disasters in society in the future, and the Kuwaiti society may not be able to handle the disastrous consequences resulting from the conditions of this category in the future unless it hastens to find a radical solution ending in the naturalization of the members of this category and integration them into the political and economic life of the Kuwaiti community (Essam Abdualshafi, 2012).

In addition, the supporters of this view do not stop at the limits of alerting of the dangers that can be generated by the process of rejection and exclusion of (the Bedoons), but they alert to the many positive aspects in the process of enabling this category of full citizenship. The leaders of this trend are moving towards accepting (the Bedoons) and granting them the right to citizenship on an intellectual ground centered on the following points:

a) The process of Citizenization and naturalization can cut off the external interference in the affairs of the state, especially some countries find in this issue the pretext of direct interference in the internal affairs of the state. This also can cut the interference of human rights organizations, which continue to criticize Kuwait and offend its reputation in the various international forums, calling for granting (the Bedoons) their political and social rights (Al-Wiqyan, 2007: 93).

b) The naturalization of (the Bedoons) helps to solve the demographic imbalance caused by the intensive presence of the expatriate workers as the Bedoons represent a homogenous segment of the Kuwaiti society intellectually, mentally, and linguistically, unlike the expatriate workers; so 
this category can be a vital alternative for the expatriate workers in that it could keep the society away from their dangers and their security threats.

c) The naturalization of (the Bedoons) and granting them the right to citizenship confirms and enhances the national security because it will necessarily reduce the high rates of crime and deviation resulting from the need, poverty, repression, and frustration.

d) The process of naturalization and citizenization will enable the state to find solutions to many problems resulting from family disintegration, crime, the marriage of a Kuwaiti woman to one of the members of this category, and a large number of cases resulting from the existence of this category for a half of century (Al-Anzi, 1994: 132).

e) The process of naturalization will reinforce the national security and strengthen the concept of citizenship it will cut the way for the members of this category to be a part of any external affiliations, which results from the sense of injustice and internal discrimination, and will give the members of this category moral and ideological immunity against all the forms of extremist affiliations that are hostile to the state and homeland.

f) The process of naturalization will lead to the development of society and improvement of the economic and financial life in Kuwait because (the Bedoons) do not know other than Kuwait as their homeland, and therefore their financial movement will take place at home and not subject to remittance abroad as in the case of the expatriate workers who transfer their full savings abroad, which deprives the country from huge financial revenues that were supposed to remain within the borders of the economy inside the state and not outside (Al-Anzi, 1994a: 228).

g) There is no doubt that granting of the citizenship rights will strengthen the values of loyalty to the homeland and will push the members of this category to sacrifice all they have for their homeland (Kuwait), doing everything they can to uphold the honor of the homeland and raise its banner (Ali Abdualfatah Al-Hawarni, 2009: 62).

\section{Kuwaiti Political Activity and the Rights of the Stateless}

The Kuwaiti arena is witnessing today, as yesterday, a great political activity to demand the rights of (the Bedoons), and this claim comes from government figures and deputies in the National Assembly who call for closing the file of (the Bedoons) by granting them full political, social, and civil rights. Elite of 100 Kuwaiti thinkers and journalists, most of whom are university professors and $\mathrm{PhD}$ holders, has filed a petition in October 2008 demanding the National Assembly and the government to grant (the Bedoons) their political rights, as 
Kuwait is witnessing continuous cultural and parliamentary political seminars to demand radical solutions to (the Bedoons) problem in Kuwait (Ghanim, Al-Najar, 2003).

It can be said the Kuwaiti intellectuals, thinkers and deputies, a large number of state men, and a large number of members of the ruling family demand political and humanitarian solutions to the positions of the Bedoons and granting them civil and social rights, as many Kuwaiti thinkers and public stakeholders have always presented systematic solutions to the problem of (the Bedoons) in Kuwait.

Importantly, a new look at the problems of naturalization and citizenship in the Gulf societies and Peninsula should be proposed for discussion, not only among the educated elites but also among the popular circles providing that this discussion is based on practical ideas that take into account the interests of these communities on the one hand and the global trend on the other hand (Al-Hawarni, 2009: 64).

Those interested in finding a fair solution to the problem of (the Bedoons) should take into consideration the fact that many of them have spent long periods in these communities in terms of the (international standards) and many of them have worked and are still working in their security and defense agencies and, therefore, if these countries have relied upon them for their security and defense, they had better grant them their nationality. It is also necessary to avoid the emergence of (the Bedoon) phenomenon by solving the origin of the issue, especially in some of the Gulf societies where there is a lot of discussion about the existence of this category.

An important thing to be noted is that a large number of politicians in Kuwait are calling for granting (the Bedoons) their social and human rights without hesitation, and more importantly the political life in Kuwait has registered an enthusiastic activity for the sons of the royal family and the people in power to confer (the Bedoons) their rights, and the examples of this initiation are many (Ghanim al-Najar, 1996: 79).

It is also noted that the political and social trend that calls for finding radical solutions to (the Bedoons) is rising at the expense of the trend that denies their rights and naturalization; this is what the political and parliamentary activities in Kuwait are predicting and what the activities of the Kuwaiti human rights organizations are increasingly confirming. This trend gets its great legitimacy in Kuwait from the sympathy of the public opinion with the rights of this category's members. 


\section{Trends of the Kuwaiti Public Opinion towards the Stateless}

The public opinion has been fluctuated on the constant rhythms of ideological activities on this issue. The public opinion in Kuwait has been and is still captive to two narratives about the Bedoons: the official narrative that surrounds them and the legal narrative that favors and supports them. And between both narratives is the absence of the objective rational view that could put (the Bedoons) in the right place of the political and social equation (AlNajar, 1996: 85).

In this context, the intensification of counter-propaganda and other pro for their issue can be seen, and this ideological conflict included the activities of propaganda, advertisement, media, rumor and counter-media. This media reality could be seen during the Iran-Iraq war in 1985, when a group of the Bedoons was accused of loyalty to Iran, and this narrative had a great negative impact on the reality of the members of this category, placing them in the dock (Al-Anzi, 1994: 142).

Here, (the Bedoons) find themselves between two propagandas, two views, and two positions, which has, in turns, a great impact on the fluctuation of Kuwaiti public opinion, especially the public opinion is known for its tendency to generalize in the various propagandistic issues for (the Bedoons) have experienced the bitterness of the negative attitude of the government and people, which puts them in a very difficult and complex humanitarian situation.

After a period of time, the new organized Bedoons' activities appeared in the media, political, and syndicalist levels that began to demand the lifting of the legal siege imposed on their existence, and (the Bedoons) managed through the internet, newspapers, and human organizations to impose a new reality of a great support for their cases nationally, locally, and globally (Ashosh \& Bakhashab, 1990: 261).

(The Bedoons) were able to exercise their democratic role in the Kuwaiti parliamentary election, where (the Bedoons) form an electoral force due to the relations of kinship, marriage, and affiliation with the Kuwaiti tribes, which deputies realized later. This has played a major role in influencing the Kuwaiti public opinion. Yet the Bedoons have been let down in more than a parliamentary council, where some deputies have broken their promises or could not fulfill what they announced in their election campaigns.

This has been reinforced by the presence of the elite of Kuwaiti thinkers and intellectuals who have supported (the Bedoons) and sympathized with their case, flooding the cultural scene with cultural discourse which demanded 
the fairness to this social group and granting them their political and social rights immediately. Consequently, this affects the Kuwaiti public opinion, which appeared to rise positively among the positive attitudes towards the issues of this marginal social category (al-Najar, 1996: 90).

\section{CONCLUSION}

In conclusion, it can be said that the issue of the stateless is a very complex issue in a way that makes it peerless in comparison with other contemporary, social, and political issues in the Arab Gulf. This problematic situation is highlighted in the definition of (the Bedoons), where the definitions intersect and the perceptions contradict, and in the statistical complexities with their paradoxes and contradictions, this problematic nature is also highlighted in the ideological struggle that rages in the various councils and squares and in the conditions related to human rights and national security and the tragic situation of this category at the various social and life levels.

Whatever the depth and severity of this problem, the influential people in Kuwait promise to find appropriate solutions for the members of this category and their human conditions. All the internal political indicators show the approaching of the objective treatment of this issue under the dome of Parliament where the committees are formed and prepared to close the outlets and entryways of this case, and if there is a treatment, it must be based on the international, constitutional, and humanitarian standards in Kuwait.

Therefore, the time has now come to stop giving priority to the origin (the origin of the Bedoons), which provokes the emotions and sentiments since the Bedoons are residing in Kuwait, in which they were born, they were living in its embrace and raised to the values of allegiance to its land and its people, young or old; indeed they are a social entity embedded deeply in the existential fabric of Kuwait's land and people.

The issue of the stateless has been brewed today in the cycle of deliberation and discussion and filed with visions, analysis and research, and the state has to find a radical solution which is not unreachable since it is of two solutions the third of which is a combination of the first and second. The first is to confer citizenship to those Bedoons according to the international standards, and if not, and this is a matter determined by the state, the state should grant this category more human and social rights, or the solution may be of two things: granting nationality to those who deserve and prove their Kuwaiti origins and embedment to the land of Kuwait and its values, and then giving full human 
rights to those on whom time imposed to belong to this country and live in the embrace of this precious land.

\section{REFERENCES}

Ahmed Abdualhameed Ashosh \& Omar Abu Bakr Bakhashab (1990). Nationality Provisions and Foreigners Center in Gulf Cooperation Council: A Comparative Study, $1^{\text {st }}$ edition. Alexandria: University Youth Foundation.

Ali Abdualfatah Al-Hawarni (2009). "The Bedoons: Old Problem and New Implications," Emirate Center for Studies and Information, 15 March 2009.

Essam Abdualshafi (2012). "The Issue of the Bedoons in Kuwait: Reading in the Internal and External Dimensions," Al-Rai Electronic Newspaper, published on 02 July 2012.

Fahd Al-Mikrad (2005). Development of the Political and Economic Development in Kuwait. Kuwait: Arabic Open University.

Faris Matar Al-Wiqyan (2007). Stateless People in Kuwait: the Crisis and its Repercussions. Kuwait: Center for Strategic and Islamic Studies, Kuwait University.

Ghanim Al-Najar (1996). The Issue of the Statelessness in Kuwait: Development and Future Possibilities. Kuwait: Dar al-Salasel for Publishing and Distribution.

Ghanim, Al-Najar (2003). "A Precise Detailed Study of the Bedoons," Al-Rai Electronic Newspaper, Kuwait, 28 May 2003.

Hasan al-Hadawi (1973). Nationality and the Foreigners Center and their Provisions in the Law of Kuwait, $1^{\text {st }}$ edition. Damascus: Dar al-Qalam.

Hussam Adeen Fathi Nasif (1996). The Legal Center for Foreigners: A Comparative Study. Cairo: Dar al-Nahdha al-Arabia.

Mohammed Husain Al-Yusufi (2004). "Why Do the Gulf People Oppose Naturalization?” Arabic Times Magazine, No. 261, January. P. 6-10.

Qadri Abdulaziz (2003). Human Rights in the International Law and International Relations, Contents and Mechanisms. Baghdad: Dar Homa for Publishing and Distribution.

Rashid Al-Anzi (1994a). (The Bedoons) in Kuwait: A Legal Study of their Residence Project. Kuwait: Dar Qirtas.

Rashid Al-Anzi (1995). A Study of the General Theory of Nationality and Princely Decree, No. 15 of 1959, $1^{\text {st }}$ edition. Kuwait: Concerning Kuwaiti Nationality and its Amendments. 
Rashid Hamad Al-Anzi (1994). "Legitimacy of the Bedoon Residence or the Stateless in Kuwait," al-Huquq Magazine, No. 1, Kuwait: Dar Qirtas for Publishing and Distribution.

Sami Khalifa (2008). "The Bedoons in Kuwait between Civil Rights and Naturalization," al-Rai Newspaper,http://www.alraimedia.com/Alrai/ Article.aspx?id=84965.13/10/2008.

Shams Adeen al-Wakeel (1991). Nationality and the Foreigners Center, $2^{\text {nd }}$ edition. Alexandria: Mansha'at al-Ma'aref. 
Journal of Shariah Law Research (JSLR) 